BJP 180-12/5/2006-ANISH-167162

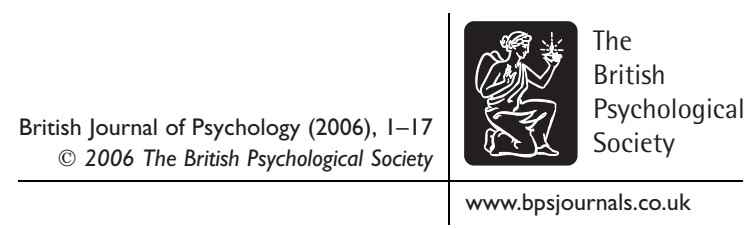

\title{
Belief in psychic ability and the misattribution hypothesis: A qualitative review
}

\author{
Richard Wiseman ${ }^{1}$ and Caroline Watt ${ }^{2}$ \\ 'University of Hertfordshire, UK \\ ${ }^{2}$ University of Edinburgh, UK
}

\begin{abstract}
This paper explores the notion that people who believe in psychic ability possess various psychological attributes that increase the likelihood of them misattributing paranormal causation to experiences that have a normal explanation. The paper discusses the structure and measurement of belief in psychic ability, then reviews the considerable body of work exploring the relationship between belief in psychic ability, and academic performance, intelligence, critical thinking, probability misjudgement and reasoning, measures of fantasy proneness and the propensity to find correspondences in distantly related material. Finally, the paper proposes several possible directions for future research, including: the need to build a multi-causal model of belief; to address the issue of correlation verses causation; to resolve the inconsistent pattern of findings present in many areas; and to develop a more valid, reliable and fine-grained measure of belief in psychic ability.
\end{abstract}

Surveys suggest that approximately $50 \%$ of Americans believe in the existence of extrasensory perception (e.g. Newport \& Strausberg, 2001), and that similar levels of belief exist throughout much of Western Europe and in many other parts of the world (e.g. Haraldsson, 1985). Attempts to identify the mechanisms underlying the formation of such beliefs have adopted one of three theoretical perspectives. Some of the research has adopted a motivational perspective and examined whether such beliefs develop, in part, because they fulfil a need for control (e.g. Irwin, 1992; Lawrence, Edwards, Barraclough, Church, \& Hetherington, 1995), or form an integral part of a religious or philosophical world-view (e.g. Haraldsson, 1981; Thalbourne \& Hootkooper, 2002). A second line of work has argued that psychic abilities may actually exist, and that some beliefs about such abilities may therefore be the result of people experiencing genuine paranormal phenomena (e.g. Alcock, Burns, \& Freeman, 2003; Irwin, 2004; Radin, 1997). A third strand of research has examined the notion that people tend to believe in psychic ability because they possess psychological attributes that make them

* Correspondence should be addressed to Professor Richard Wiseman, University of Hertfordshire, College Lane, Hatfield, Hertfordshire, ALIO 9AB, UK (e-mail: R.Wiseman@herts.ac.uk). 
BJP 180-12/5/2006-ANISH-167162

more likely to misattribute paranormal causation to normal experiences. This paper presents a qualitative and critical review of research relating to this third perspective.

The first section of the paper discusses the structure and measurement of belief in psychic ability. The second section reviews research exploring the relationship between belief in psychic ability and academic performance, intelligence, critical thinking, probability misjudgement and reasoning, a propensity to find correspondences in distantly related material, and measures of fantasy proneness. Finally, the paper proposes several possible directions for future research.

\section{The structure and measurement of belief in psychic ability}

There are two main types of alleged psychic ability: extra-sensory perception and psychokinesis (Irwin, 2004). Extra-sensory perception (ESP) is the apparent ability to receive information via a channel of communication not presently recognized by mainstream science, and includes alleged clairvoyance (in which the information was not known to anyone else), telepathy (in which the information was known to another person) and precognition (in which the information relates to a future event). Psychokinesis (PK) is the apparent ability to influence physical objects or biological systems using unknown means, and encompasses a wide range of alleged phenomena, including causing objects to levitate, dice to roll sixes at above chance levels and paranormal healing.

Although some researchers have created their own measures of belief in such abilities (e.g. Blackmore \& Moore, 1994; Sheils \& Berg, 1977; Wiseman \& Morris, 1995), most of the work in this area has employed either the Australian sheep-goat scale ${ }^{1}$ or the Paranormal belief scale (Goulding \& Parker, 2001).

The most recent version of the Australian Sheep-Goat scale (ASGS) contains 18 statements, with respondents indicating their level of agreement or disagreement with each statement using a visual analogue scale (Thalbourne \& Delin, 1993). Sixteen of the items relate to people's belief in, or alleged experience of, ESP and PK (e.g. 'I am completely convinced that ESP exists' and 'I am completely convinced that it is impossible to send a "mental message" to another person'), with the remaining two referring to belief in the after-life ('I believe in life after death' and 'I believe that some people can contact the spirits of the dead'). Although there is some evidence that the scale may contain three distinct subscales (relating to ESP, PK and life after death), scores on the individual items are very highly correlated with one another, such that the vast majority of researchers, including those who developed the scale, use the questionnaire to provide a single measure of participants' belief in psychic ability (e.g. Thalbourne, 1995a, 1995b; Thalbourne \& Delin, 1993; Thalbourne, Dunbar, \& Delin, 1995).

The Paranormal belief scale (PBS; Tobacyk \& Milford, 1983; later slightly revised by Tobacyk, 1988) contains 26 items relating to a very wide range of alleged paranormal phenomena (including, e.g. unidentified flying objects, superstition, ESP, precognition, the existence of hell and the Loch Ness monster), with people being asked to respond to each item on a 7-point scale anchored by strongly agree and strongly disagree. The scale contains a number of items directly relating to alleged psychic ability, including those concerning PK, mind-reading and precognition (e.g. 'mind-reading is not possible'

\footnotetext{
'The unusual title of this scale comes from Schmeidler (1945) who, using a biblical metaphor, coined the term 'sheep' to refer to those who believe in the possibility of ESP and 'goats' to refer to disbelievers.
} 
BJP 180-12/5/2006-ANISH-167162

and 'Some psychics can accurately predict the future'). Tobacyk and Milford originally argued that the PBS contained seven subscales (traditional religious belief, psi, witchcraft, superstition, spiritualism, extraordinary life forms and precognition), with scores on three of these (psi, spiritualism and precognition) providing measures of belief in psychic ability. However, several researchers have since challenged the way in which Tobacyk and Milford analysed and interpreted the psychometric properties of the PBS, arguing that the items relating to belief in psychic ability are best viewed as a single factor. (Hartman, 1999; Lange, Irwin, \& Houran, 2000; Lawrence, 1995a, 1995b; Lawrence \& De Cicco, 1997; Lawrence, Roe, \& Williams, 1997, 1998; Tobacyk, 1995a, 1995b; Tobacyk \& Thomas, 1997). Thus, Lawrence et al. carried out an exploratory factor analysis of responses to the PBS, noting that a five-factor model provided a better fit of the data than seven factors, with one of the five factors containing items relating to belief in psychic abilities. Lawrence et al. report obtaining the same results in a second, confirmatory, factor analysis. Likewise, Lange et al. report carrying out a Rasch scaling of the PBS, and argue for the existence of two clusters of items: new age philosophy (NAP; containing 11 items drawn almost entirely from the psi, spiritualism and precognition subscales) and traditional paranormal beliefs (TPB; containing 5 items drawn from the traditional religious belief and witchcraft subscales). This two-factor model has recently been widely adopted by several researchers examining the correlates

Q1 of belief in the paranormal (e.g. Houran \& Lange, 2001; Irwin, 2003a, 2003b; Irwin, Thalbourne, 2001).

There is also considerable evidence suggesting that scores on the various scales described above are highly correlated with one another. For example, correlations between participants' scores on the ASGS and the psi, precognition and spiritualism subscales of the PBS range from approximately .6-.7 (Thalbourne, 1995a; Thalbourne et al., 1995), and Thalbourne (2001) reports a correlation of .77 between participants' scores on the ASGS and the PBS items making up Lange et al's (2000) measure of NAP. Also, the vast majority of other scales designed to measure belief in psychic ability (e.g. Blackmore \& Moore, 1994; Sheils \& Berg, 1977; Wiseman \& Morris, 1995) contain items that are worded in a very similar way to those items making up the ASGS and PBS. For example, the Paranormal belief scale devised by Blackmore and Moore contains 10 statements concerning the existence of psychic ability (e.g. 'extra-sensory perception exists' and 'I have had at least one premonition about the future that came true, and which was not just a coincidence'). Blackmore and Moore calculate the mean score for each participant and use this as a general measure of belief in psychic ability. Likewise, in the 5-item questionnaire constructed by Sheils and Berg, participants are asked to indicate their belief about telepathy, PK, precognition, astral projection and psychic healing. Again, each participant's scores on these 5 items are then combined to produce an overall measure of belief. Many of these questionnaires have not undergone the type of extensive psychometric testing that has been carried out with the ASGS and PBS. However, the small amount of research that has examined the relationship between different measures of belief in psychic ability has reported that people's scores on these scales tend to be highly correlated with their scores on the ASGS and PBS (e.g. Irwin, 1985 , reports a .74 correlation between participants' scores on ASGS and the questionnaire constructed by Sheils \& Berg, 1977).

In short, some of the most frequently employed questionnaires designed to measure paranormal belief contain items relating to a diverse range of phenomena, including, for example, ESP, astrology, the afterlife and luck. This review focuses on just one of these factors, namely, belief in psychic ability. For the reasons outlined above, this belief will be 
BJP $180-12 / 5 / 2006-$ ANISH-167162

treated as a single dimension, and the ASGS, Psi, Spiritualism and Precognition subscales of the PBS, the PBS items making up Lange et al's measure of NAP, and some of the less widely used questionnaires described above will be viewed as valid measures of this belief.

\section{The misattribution hypothesis}

The misattribution hypothesis assumes that people have developed beliefs in psychic ability because they have misattributed psychic causation to normal experiences (e.g. Alcock, 1981; Blackmore, 1992). This paper evaluates this hypothesis by examining the relationship between belief in psychic ability and four processes that may lead to such misattribution; namely, poor general cognitive abilities, probability misjudgements, propensity to find correspondences in distantly related material and fantasy proneness. Each of these areas will be reviewed in turn.

\section{General cognitive ability}

Some researchers have speculated that believers may, in general, have poor cognitive abilities compared with disbelievers and therefore be less able to accurately judge whether alleged psychic phenomena have normal explanations (e.g. Alcock, 1981; Blackmore, 1992; Marks, 1988). A diverse range of research has evaluated this hypothesis, including studies examining the relationship between belief in psychic ability and academic achievement, intelligence and reasoning.

Several studies have investigated the relationship between belief in psychic ability and various measures of academic achievement, including participants' course grades, Q2 SAT scores, exam performance and highest level of educational attainment. Although many of these studies have reported that believers show significantly lower levels of academic performance than disbelievers (Gray, 1987; Messer \& Griggs, 1989; Musch \& Ehrenberg, 2002; Otis \& Alcock, 1982; Pasachoff, Cohen, \& Pasachoff, 1970), the overall pattern of results is inconsistent, with some researchers failing to replicate this finding (Thalbourne \& Nofi, 1997) and others reporting believers outperforming disbelievers (Emmons \& Sobal, 1981; Haraldsson, 1985; Tobacyk, Miller, \& Jones, 1984). Studies examining the relationship between belief in psychic ability and scores on intelligence tests have also yielded mixed findings, with some researchers reporting negative correlations (Smith, Foster, \& Stovin, 1998), others failing to find this relationship (Thalbourne \& Nofi, 1997; Wiseman \& Watt, 2002) and, in at least one study, believers obtaining significantly higher scores than disbelievers (Jones, Russell, \& Nickel, 1977).

A small amount of work has also examined belief in psychic ability within academia. Some studies have reported that people with a background in science tend to express lower levels of belief than those involved in the humanities (Happs, 1987; Otis \& Alcock, 1982; Padgett, Benassi, \& Singer, 1981). However, again, the overall pattern is far from clear-cut, with one study reporting that students studying the biological sciences held higher levels of paranormal belief than their humanity-based counterparts (Salter \& Q3 Routledge, 1971), and other research finding that the majority of scientists teaching at American colleges or universities rating ESP as a 'likely possibility' (McClenon, 1982; Wagner \& Monnet, 1979).

The same rather confused pattern of findings has also emerged from work investigating belief in psychic ability and scores on critical thinking tests. Once again, 
BJP 180-12/5/2006-ANISH-167162

some researchers have reported disbelievers obtaining significantly higher scores than believers (e.g. Alcock \& Otis, 1980), but others have failed to replicate these results (Royalty, 1995). A small amount of research has also examined belief in psychic ability and performance on more ecologically valid measures of critical thinking; namely, the way in which participants assess reports of scientific experiments. In the first of these studies, Alcock and Otis asked participants to critically evaluate short research articles describing an experiment into either PK or pain tolerance. Contrary to expectations, they found no significant differences between the performance of believers and disbelievers. Gray and Mill (1990) reported a similar study in which participants were asked to identify methodological problems in mock scientific papers, and found that believers exhibited significantly less critical thinking skills than disbelievers. However, Roe (1999) has criticized this study, arguing that the findings may have been the result of either cognitive dissonance or a procedural artifact. Roe also reported his own study that controlled for these issues by asking both believers and disbelievers to rate mock scientific papers that were either pro or anti ESP. Roe found no significant differences between the way in which believers and disbelievers assessed these papers, with both groups showing a significant tendency to rate papers that were incongruent with their prior beliefs as less competently conducted than papers in line with their beliefs. In a conceptually similar study, Korpan, Bisanz, Bisanz, and Henderson (1997) had participants assess short newspaper reports of scientific studies into either psychic ability or more mainstream topics, but again found few differences in how believers and disbelievers carried out this task.

A slightly more consistent pattern of results has emerged from work examining the relationship between belief in psychic ability and performance on syllogistic reasoning tasks (i.e. tasks in which participants are presented with a pair of statements, followed by a conclusion, and asked to indicate whether the conclusion could be derived logically from the statements). The majority of research has found that disbelievers tend to perform significantly better on these types of tasks than believers (Polzella, Popp, \& Hinsman, 1975; Roberts \& Seager, 1999; Wierzbicki, 1985; Wiseman \& Watt, 2002), with Q3 only one study failing to replicate this relationship (Irwin, 1991).

Thus, although there is some evidence of disbelievers outperforming believers on syllogistic reasoning tasks, the majority of the work in this area has produced a somewhat inconclusive set of results. However, drawing any strong conclusions from this body of work is problematic, in part, because many of the studies have employed rather general measures (e.g. participants' IQ scores or SAT results) that do not directly test the hypothesis that believers are less able than disbelievers to evaluate evidence of alleged psychic ability. As a result, there is a strong need for future work in this area to involve measures that provide a more direct test of this hypothesis including, for example, participants' level of scientific training, ability to generate and evaluate alternative hypotheses, and so on. However, the mixed findings from the few studies that have used more ecologically valid measures (e.g. asking participants to assess mock scientific reports relating to psychic phenomena) suggest that there is no reason to assume that the results of such work will provide a dramatically different pattern of findings. In short, with the possible exception of the relationship between belief in psychic ability and performance on syllogistic reasoning tasks, the existing literature does not support the notion that believers and disbelieves in psychic ability differ in their levels of general cognitive functioning. 
BJP $180-12 / 5 / 2006-$ ANISH-167162

\section{Probability misjudgement}

People can erroneously attribute psychic causality to an unusual experience (e.g. thinking of a distant friend only to receive a telephone call from that person moments later) if they underestimate the likelihood of that experience happening by chance, and therefore reject coincidence as a tenable explanation (Morris, 1986). As a result, some researchers have argued that people who make poor probability judgments may be more likely than others to view their experiences as psychic (Blackmore, 1992; Blackmore \& Troscianko, 1985).

Researchers have tested this hypothesis by examining the relationship between belief in psychic ability and performance on various probability judgment tasks, such as asking about the relative likelihood of certain scenarios (e.g. 'Is throwing 10 dice at the same time and getting 10 sixes more or less likely than throwing 1 dice 10 times and obtaining 10 successive sixes?') or generating stings of 'random' numbers that are later analysed for biased sequences. The majority of this work suggests that, compared with disbelievers, believers tend to underestimate the statistical likelihood of the scenarios, and show a greater avoidance of repetition when generating 'random' strings, thus resulting in more biased sequences (Blackmore \& Troscianko, 1985; Bressan, 2002; Brugger, 1997; Brugger, Landis, \& Regard, 1990; Brugger, Regard, \& Landis, 1991; Brugger, Regard, Landis, Krebs, \& Niederberger, 1994; Musch \& Ehrenberg, 2002), although a small number of studies have failed to replicate this finding (Blackmore, Galaud, \& Walker, 1994; Houtkooper \& Haraldsson, 1997; Matthews \& Blackmore, 1995) and one study has reported believers outperforming disbelievers (Lawrence, 1990-1991).

Blackmore (1997) adopted a somewhat different approach to assessing the probability misjudgement model, examining the relationship between belief in psychic ability and the 'Barnum' effect. This effect occurs when people judge very general personality statements (e.g. 'You have a great deal of untapped creative potential') as a more accurate description of themselves than others. Blackmore hypothesized that this effect could be due to people misjudging the probability of the statements being endorsed by others, and speculated that believers may therefore be more prone to the effect than disbelievers. Blackmore presented both believers and disbelievers with 10 general statements (e.g. 'You have a scar on your left knee'), asked them to imagine presenting them to a randomly selected person on the street and then guess how many of the statements would be endorsed by the imaginary person. Contrary to expectations, the results showed no difference in the probability estimates given by believers and disbelievers.

Musch and Ehrenberg (2002) recently examined whether probability judgment may be related to more general cognitive ability. In addition to collecting data on participants' probability judgments, the researchers also created a measure of general cognitive ability (secondary school grade average weighted across several subjects). Although significant negative correlations were found between belief in psychic ability and probability misjudgements, these were reduced to non-significance once the researchers controlled for general cognitive ability. As a result, the authors argue that poor cognitive ability may underlie the apparent relationship between belief in psychic ability and probability misjudgements.

In short, the probabilistic judgment tasks that have tended to show a significant relationship with belief in psychic ability appear somewhat artificial (e.g. assessing the likelihood of a die producing a certain sequence of numbers), whereas more ecologically valid tasks (e.g. assessing the probability of the type of statements made by 
BJP 180-12/5/2006-ANISH-167162

a psychic being accurate) have failed to replicate these effects. As with the literature assessing the relationship between belief in psychic ability and general cognitive functioning, there appears to be a strong need for more ecologically valid studies that provide a more direct test of the hypothesis under consideration. However, unlike the literature on general cognitive functioning, the existing literature provides some evidence to support the notion that disbelievers tend to outperform believers on tasks involving probabilistic judgments and statistical thinking.

\section{The propensity to find correspondences in distantly related material}

People often believe that they have had a psychic experience when there appear to be inexplicable correspondences between their thoughts and events in the real world (Morris, 1986). As a result, some researchers have hypothesized that the more an individual possesses the ability to find connections between their experiences and actual events, the more likely they are to view their experiences as psychic (see, e.g. Blackmore, 1992; Brugger \& Graves, 1997a; Houran \& Lange, 1998).

Support for this hypothesis comes from several studies in which participants have been presented with images of random dot patterns and asked to try to identify Q4 drawings embedded in the image (Blackmore \& Moore, 1994; Brugger et al., 1993b). As predicted, believers were significantly more able than disbelievers to identify nonexistent drawings. These results have been conceptually replicated in several other studies in which participants have been asked to find meaningful connections between a variety of randomly paired stimuli, including line drawings (Brugger, 1992, cited in Brugger \& Taylor, 2003; Brugger et al., 1994; Wiseman \& Smith, 2002) and nouns (Pizzagalli, Lehmann, \& Brugger, 2001).

In short, these studies suggest a reliable relationship between belief in psychic ability and the finding of connections between distantly related visual and verbal material. These results support the findings from other research in which believers have reported higher scores than disbelievers on a variety of self-report measures of creativity (Thalbourne, 1998; Thalbourne \& Delin, 1994). Unlike the previous two sections exploring general cognitive functioning and probability judgments, believers' increased ability to find correspondences between events and experiences, and therefore attribute psychic causation to such experiences, does not necessarily imply that such attributions are erroneous. Indeed, it could be argued that disbelievers are experiencing genuine psychic phenomena but failing to notice them because of their inability to detect meaningful connections.

Additional work on this topic has explored how possible differences in the hemispheric activity of believers and disbelievers might provide a neurological explanation for these findings. Given the significant body of research suggesting that the right hemisphere is associated with the processing of distantly related material (e.g. metaphors and humour, certain aspects of creativity), some researchers have argued that the type of right hemisphere over-activation exhibited by believers may explain why they are better able to find meaningful connections between experiences and events, and thus be more likely to believe in psychic ability (e.g. Brugger \& Taylor, 2003). Various studies have reported evidence to support this notion. For example, Q5 Brugger, Gamma, Müri, Schäfer, and Taylor (1993a) had both disbelievers and believers complete a lateralized tachistoscopic lexical-decision task. Believers exhibited significantly enhanced lexical-decision accuracy in the left visual field/right hemisphere compared with non-believers. Likewise, Pizzagalli et al. (2000) measured EEG activity in 
BJP 180-12/5/2006-ANISH-167162

8

Richard Wiseman and Caroline Watt

both believers and disbelievers during a 4-minute, eyes-closed, resting period. Compared with disbelievers, believers showed relatively higher right hemisphere activation and reduced hemispheric asymmetry of functional complexity. Finally, Brugger and Graves (1997b) had blindfolded participants attempt to tactually bisect a rod. Consistent with the notion of over-activation in the right hemisphere, participants' levels of belief in psychic ability were positively correlated with the degree of leftward deviation in the bisection task.

Brugger and Taylor (2003) have also argued that high scores on tasks involving perceived connections in distantly related material are the result of the type of disinhibition of semantic network activation that may act as one basis for schizophrenic thought disorder, and that this work thus has the potential to help provide an insight into the positive relationship between belief in psychic ability and a propensity for schizophrenia (Peltzer, 2002, 2003; Thalbourne, 1998; Thalbourne et al., 1995; Thalbourne \& French, 1995). However, several researchers have stressed that these findings should not be used to pathologize belief in the paranormal, but instead help clarify the distinction between relatively healthy forms of such beliefs and those that might be associated with psychological ill-health (e.g. Goulding, 2004, 2005; Williams \& Irwin, 1991).

\section{Fantasy proneness}

Fantasy proneness entails a propensity to become so deeply absorbed in a fantasy that it is difficult to know whether the experience is purely imaginary or caused by an external source (Lynn \& Rhue, 1988). Some researchers have speculated that fantasy-prone people are more likely to both experience certain types of unusual quasi-perceptual phenomena (e.g. visions, hallucinated voices and apparitions) and, because of the extreme vividness of these experiences, erroneously conclude that such events actually happened and were psychic in origin (Blackmore, 1984; Marks, 1988). This hypothesis predicts that believers will obtain higher scores than disbelievers on measures relating to fantasy proneness, including, for example, hypnotizability, suggestibility, imagery skills, absorption and dissociation.

Several studies have found positive correlations between belief in psychic ability and a range of measures assessing hypnotisability (Palmer \& Van Der Velden, 1983; Pekala, Kumar, \& Marcano, 1995; Thalbourne, 1995b; Wagner \& Ratzeburg, 1987); however, other studies have failed to replicate these findings (Pekala et al., 1995; Saucer, Cahoon, \& Edmonds, 1992). Wiseman, Greening, and Smith (2003) carried out a more naturalistic examination into suggestion within the context of a mock séance. During these studies, an actor (playing the role of a medium) suggested that a stationary table was levitating. Participants' prior belief in the paranormal predicted the degree to which these suggestions affected their recall of the séance, with believers exhibiting significantly higher levels of suggestibility than disbelievers.

Only a small number of studies have investigated the relationship between belief in psychic ability and imagery abilities. Diamond and Taft (1975) found a positive and significant correlation between belief in psychic ability and the Betts Questionnaire Upon Mental Imagery, and Dixon, Labelle, and Laurence (1996) reported similar findings using the preference for an imagic cognitive style. More recently, however, researchers have failed to find any relationship between belief in psychic ability and imagery-based tasks designed to induce false memories (Blackmore \& Rose, 1997; Rose \& Blackmore, 2001). 
BJP 180-12/5/2006-ANISH-167162

Research has revealed positive, and often reasonably large, correlations between scores on the Inventory of Childhood Memories and Imaginings (the most frequently used measure of fantasy proneness) and belief in psychic ability (Irwin, 1990, 1991b). Several studies have also reported significant correlations between belief in psychic ability and scores on the most widely used measure of absorption, the Tellegen absorption scale (Council, Greyson, \& Huff, 1988; Palmer \& Van Der Velden, 1983); however, this was not confirmed in a later study by Makasovski and Irwin (1999), which used a subset of items from the Dissociative experiences scale to index 'psychological absorption'. Finally, several researchers have reported positive and significant correlations between belief in psychic ability and several different measures of dissociative tendencies (e.g. Irwin, 1994; Makasovski \& Irwin, 1999; Pekala et al., 1995).

In short, there is considerable evidence to support a relationship between belief in psychic ability and several concepts related to fantasy proneness. These findings, although consistent, should perhaps be treated with some caution given that several researchers have noted how many of the measures employed are intercorrelated and thus may reflect the operation of a single underlying concept (see, e.g. Kirsch \& Council, 1992). Indeed, Thalbourne $(1998,2000,2001)$ has published a considerable body of work arguing that the single concept of 'transliminality' (derived from the Latin word trans, meaning across, and limen, meaning threshold), underpins a wide range of such factors including frequency of dream interpretation, fantasy proneness, absorption, magical ideation and mystical experiences.

\section{Looking into the future}

\section{The need to build on consistent patterns of existing findings}

Some of the research areas outlined above have obtained consistent results and thus reveal important insights in the psychology of belief in psychic ability. For example, believers have consistently obtained higher scores than disbelievers on several measures of fantasy proneness and exhibit a propensity to find correspondences in distantly related material. These findings could be interpreted as supporting the notion that some people may come to believe in psychic ability because they incorrectly attribute paranormal causation to certain types of normal experiences. In addition to continuing to explore the type of factors that influence these effects, future work should build on these findings in two ways.

First, although existing work has demonstrated reliable differences between believers and disbelievers, the magnitude of the observed effects are relatively modest and thus there is scope to develop and assess models that provide a more comprehensive account of belief in psychic ability. It seems unlikely that a complete understanding of such beliefs will rely purely on the type of material reviewed in the previous section. Instead, it may be more beneficial for researchers to explore how the types of reliable effects identified above may interact with the type of factors investigated by researchers adopting a motivational approach to belief in psychic ability (i.e. examining the degree to which such beliefs develop because they fulfil important psychological needs or form part of a world-view). The initial findings from the small amount of work that has started to develop this type of multi-causal modelling is encouraging. For example, both Irwin (1992, 1993) and Lawrence et al. (1995) have successfully developed models that aim to predict belief in psychic ability via a combination of propensity for fantasy proneness and a strong need for control created by childhood trauma. 
BJP $180-12 / 5 / 2006-$ ANISH-167162

Second, the correlational nature of almost all of the work reviewed in the previous section makes it impossible to know whether belief in psychic ability causes, or is a result of, the various factors that are consistently associated with such beliefs (e.g. Irwin, 1985; Lange \& Thalbourne, 2002; Thalbourne, 2004; Zusne \& Jones, 1982). Future work needs to address this issue. A small number of researchers have started to explore how causal modelling might help resolve this issue (Houran, Kumar, Thalbourne, \& Lavertue, 2002; Houran, Wiseman, \& Thalbourne, 2002; Lange, 1999; Lange \& Houran, 1998). These findings, developed within the context of alleged hauntings and poltergeist activity, suggest that in certain contexts (e.g. when entering a location that has a reputation for being haunted), believers tend to selectively attend to ambiguous external (e.g. small sounds or noises) and internal (e.g. bodily changes) phenomena and, because of their beliefs, are more likely to attribute paranormal causation to these phenomena. As a result of this attribution, they then experience increased levels of fear that, in turn, motivate them to notice and attribute meaning to additional phenomena. This process has the potential to act as a positive feedback loop, with participants growing ever more fearful and, as a result, experiencing increasing amounts of 'paranormal activity'. A similar approach could be applied to many of the areas reviewed in the previous section. Although such modelling clearly has the potential to make an important contribution to the correlation versus causation debate, other types of experimental designs could also be used to help resolve the debate. Such research could involve enhancing people's performance on certain measures (e.g. critical thinking, creativity, probabilistic judgments or absorption) and examining whether this leads to predicted changes in belief in psychic ability. An alternative approach could involve changing participants' beliefs about psychic ability (e.g. by having them attend a course that presents a positive or sceptical perspective about such abilities) and then assessing the impact of this change on relevant abilities.

\section{The need to resolve inconsistent patterns in existing findings}

Much of the research reviewed in the previous section has yielded somewhat mixed and inconsistent results (e.g. the relationship between belief in psychic ability and academic performance, intelligence, critical thinking and probability misjudgement). Future research should attempt to identify and control possible sources of such inconsistency including, for example, the nature of the tasks and belief measure employed, and the context in which the work is conducted. In a rare example of the type of research required, Irwin (1993) hypothesized that the mixed patterns of results obtained in studies examining belief in psychic ability and general cognitive ability could be due to the different contexts in which the studies tend have been conducted. Irwin correctly noted that many of the investigators obtaining significantly negative correlations between belief and intelligence-related measures were sceptical of psychic abilities. He then speculated that more able and insightful participants may have detected this scepticism, suppressed their belief scores to conform to this context and thus artificially created the reported correlations. This hypothesis has been tested in two studies that have employed different procedures to systematically alter the experimental context. In the first study (Smith et al., 1998), participants completed an intelligence test, read material that was either pro or anti the existence of ESP and finally completed a measure of belief. In contrast, Wiseman and Watt (2002) had experimenters holding opposing beliefs about the existence of psychic ability administer a measure of belief, an intelligence test and reasoning task. Although neither experiment produced clear-cut 
findings in support of Irwin's hypothesis, this work illustrates the type of endeavour needed to help explore and resolve the inconsistencies that plague much of the research reviewed in the previous section.

\section{The need to develop a new measure of belief in psychic ability}

As noted near the start of this paper, a wide variety of questionnaires have been used to measure belief in psychic ability. Unfortunately, the psychometric properties of even the most commonly used measures have been the subject of considerable debate. There now exists a pressing need for researchers to develop a psychometrically valid questionnaire that provides a far more fine-grained measure of belief in psychic ability. The development of such a scale should explore whether belief in psychic ability is best represented as a single dimension or as several subscales, and carefully consider whether the measurement of such beliefs is significantly improved by incorporating additional factors including, for example, reflecting the degree of conviction with which such beliefs are held, and the evidence on which they are based (e.g. personal experiences, another person's experiences, media influence, religious influence; see Clarke, 1995; Roe, 1998).

In conclusion, a large amount of research has examined whether people who believe in psychic ability possess various psychological attributes that make them more likely to misattribute paranormal causation to normal experiences. Believers, for example, have consistently obtained higher scores on several measures of fantasy proneness, the propensity to find correspondences in distantly related material and tests of syllogistic reasoning. However, much of the research has yielded somewhat inconsistent results, including work examining the relationship between belief in psychic ability and academic performance, intelligence, critical thinking and probability misjudgement. Future research needs to build upon those areas that have produced consistent findings, incorporating this work into more comprehensive models of belief, investigating the mechanisms that underlie such findings and attempting to resolve the correlation versus causation issue. There is also a pressing need for future work to attempt to resolve the inconsistent results that have been reported in many other areas, by attempting to identify and control possible sources of such inconsistency. Finally, the entire area would greatly benefit from the development and widespread utilization of a more reliable, valid and fine-grained measure of belief in psychic ability. It is hoped that such work will help answer many of the unsolved mysteries currently associated with the formation and maintenance of such beliefs.

\section{References}

Alcock, J., Burns, J., \& Freeman, A. (2003). Psi wars: Getting to grips with the paranormal. Charlottesville, VA: Imprint Academic.

Alcock, J. E. (1981). Parapsychology: Science or magic? New York: Pergamon Press.

Alcock, J. E., \& Otis, L. P. (1980). Critical thinking and belief in the paranormal. Psychological Reports, 46, 479-482.

Blackmore, S. J. (1984). A postal survey of OBEs and other experiences. Journal of the Society for Psychical Research, 52, 225-244.

Blackmore, S. J. (1992). Psychic experiences: Psychic illusions. Skeptical Inquirer, 16, 367-376.

Blackmore, S. J. (1997). Probability misjudgment and belief in the paranormal: A newspaper survey. British Journal of Psychology, 88, 683-689. 
BJP 180-12/5/2006-ANISH-167162

\section{Richard Wiseman and Caroline Watt}

Blackmore, S. J., Galaud, K., \& Walker, C. (1994). Psychic experiences as illusions of causality. In E. W. Cook \& D. L. Delanoy (Eds.), Research in parapsychology 1991 (pp. 89-93). Metuchen, NJ: Scarecrow Press.

Blackmore, S. J., \& Moore, R. (1994). Seeing things: Visual recognition and belief in the paranormal. European Journal of Parapsychology, 10, 91-103.

Blackmore, S. J., \& Rose, N. (1997). Reality and imagination: A psi-conducive confusion? Journal of Parapsychology, 61, 321-335.

Blackmore, S. J., \& Troscianko, T. (1985). Belief in the paranormal: Probability judgements, illusory control, and the chance baseline shift. British Journal of Psychology, 76, 459-468.

Bressan, P. (2002). The connection between random sequences, everyday coincidences, and belief in the paranormal. Applied Cognitive Psychology, 16, 17-34.

Brugger, P. (1992). Subjektiver Zufall: Implikationen für Neuropsychologie und Parapsychologie. Unpublished Doctoral Dissertation, Institute for Zoology, University of Zurich.

Brugger, P. (1997). Variables that influence the generation of random sequences. Perceptual and Motor Skills, 84, 627-661.

Brugger, P., Gamma, A., Müri, R., Schäfer, M., \& Taylor, K. I. (1993a). Functional hemispheric asymmetry and belief in ESP: Towards a neuropsychology of belief. Perceptual and Motor Skills, 77, 1299-1308.

Brugger, P., \& Graves, R. E. (1997a). Testing vs. believing hypotheses: Magical ideation in the judgment of contingencies. Cognitive Neuropsychiatry, 2, 55-57.

Brugger, P., \& Graves, R. E. (1997b). Right hemisphatial inattention and magical ideation. European Archives of Psychiatry and Clinical Neuroscience, 247, 55-57.

Brugger, P., Landis, T., \& Regard, M. (1990). A sheep-goat effect in repetition avoidance: Extrasensory perception as an effect of subjective probability? British Journal of Psychology, 81, 455-468.

Brugger, P., Regard, M., \& Landis, T. (1991). Belief in extrasensory perception and illusory control: A replication. Journal of Psychology, 125, 501-502.

Brugger, P., Regard, M., Landis, T., Cook, N., Krebs, D., \& Niederberger, J. (1993b). Meaningful patterns in visual noise: Effects of lateral stimulation and the observer's belief in ESP. Psychopathology, 26, 261-265.

Brugger, P., Regard, M., Landis, T., Krebs, D., \& Niederberger, J. (1994). Coincidences: Who can say how meaningful they are? In E. W. Cook \& D. L. Delanoy (Eds.), Research in parapsychology 1991 (pp. 94-98). Metuchen, NJ: Scarecrow Press.

Brugger, P., \& Taylor, K. I. (2003). ESP: Extrasensory perception or effect of subjective probability? Journal of Consciousness Studies, 10, 221-246.

Clarke, D. (1995). Experience and other reasons given for belief and disbelief in paranormal and religious phenomena. Journal of the Society for Psychical Research, 60, 371-384.

Council, J. R., Greyson, B., \& Huff, K. D. (1988). Reports of paranormal experiences as a function of imaginative and hypnotic ability. Paper presented at the meeting of the Society for Clinical and Experimental Hypnosis, Asheville, North Carolina.

Diamond, M. J., \& Taft, R. (1975). The role played by ego-permissiveness and imagery in hypnotic responsivity. International Journal of Clinical and Experimental Hypnosis, 23, 130-138.

Dixon, M., Labelle, L., \& Laurence, R.-J. (1996). A multivariate approach to the prediction of hypnotic susceptibility. International Journal of Clinical and Experimental Hypnosis, 44 , 250-264.

Emmons, C. F., \& Sobal, J. (1981). Paranormal beliefs: Testing the marginality hypothesis. Sociological Focus, 14, 49-56.

Goulding, A. (2004). Schizotypy models in relation to subjective health and paranormal beliefs and experiences. Personality and Individual Differences, 37, 157-167.

Goulding, A. (2005). Healthy schizotypy in a population of paranormal believers and experients. Personality and Individual Differences, 38, 1069-1083. 
Goulding, A., \& Parker, A. (2001). Finding psi in the paranormal: Psychometric measures used in research in paranormal beliefs/experiences and in research on psi-ability. European Journal of Parapsychology, 16, 73-101.

Gray, T. (1987). Educational experience and belief in paranormal phenomena. In F. B. Harrold \& R. A. Eve (Eds.), Cult archaeology and creationism: Understanding pseudoscientific beliefs about the past (pp. 21-33). Iowa City: University of Iowa Press.

Gray, T., \& Mill, D. (1990). Critical abilities, graduate education (Biology vs English), and belief in unsubstantiated phenomena. Canadian Journal of Behavioural Science, 22, 162-172.

Happs, J. C. (1987). Conceptual conflict over pseudoscience: A case study involving teacher trainees and their belief in water divining. Skeptic (Australia), 7(2), 21-28.

Haraldsson, E. (1981). Some determinants of belief in psychical phenomena. Journal of the American Society for Psychical Research, 75, 297-309.

Haraldsson, E. (1985). Representative national surveys of psychic phenomena: Iceland, Great Britain, Sweden, USA and Gallup's multinational survey. Journal of the Society for Psychical Research, 53, 145-158.

Hartman, S. E. (1999). Another view of the paranormal belief scale. Journal of Parapsychology, 63, 131-141.

Houran, J., Kumar, V. K., Thalbourne, M. A., \& Lavertue, N. E. (2002). Haunted by somatic tendencies: Spirit infestation as psychogenic illness. Mental Health, Religion and Culture, 5 , 119-133.

Houran, J., \& Lange, R. (1998). Modeling precognitive dreams as meaningful coincidences. Psychological Reports, 83, 1411-1414.

Houran, J., \& Lange, R. (2001). Support for the construct validity of the two-factor conceptualization of paranormal belief: A complement to Thalbourne. European Journal of Parapsychology, 16, 53-61.

Houran, J., Wiseman, R., \& Thalbourne, M. A. (2002). Perceptual-personality characteristics associated with naturalistic haunt experiences. European Journal of Parapsychology, 17, 17-44.

Houtkooper, J. M., \& Haraldsson, E. (1997). Reliabilities and psychological correlates of guessing and scoring behavior in a forced-choice ESP task. Journal of Parapsychology, 61, 119-134.

Irwin, H. J. (1985). A study of the measurement and the correlates of paranormal belief. Journal of the American Society for Psychical Research, 79, 301-326.

Irwin, H. J. (1990). Fantasy proneness and paranormal beliefs. Psychological Reports, 66, 655-658.

Irwin, H. J. (1991a). Reasoning skills of paranormal believers. Journal of Parapsychology, 55, Q6 281-300.

Irwin, H. J. (1991b). A study of paranormal belief, psychological adjustment, and fantasy proneness. Journal of the American Society for Psychical Research, 85, 317-331.

Irwin, H. J. (1992). Origins and functions of paranormal belief: The role of childhood trauma and interpersonal control. Journal of the American Society for Psychical Research, 86, 199-208.

Irwin, H. J. (1993). Belief in the paranormal: A review of the empirical literature. Journal of the American Society for Psychical Research, 87, 1-39.

Irwin, H. J. (1994). Paranormal belief and proneness to dissociation. Psychological Reports, 75 , 1344-1346.

Irwin, H. J. (2003a). Reality testing and the formation of paranormal beliefs. European Journal of Parapsychology, 18, 15-28.

Irwin, H. J. (2003b). Paranormal beliefs and the maintenance of assumptive world views. Journal of the Society for Psychical Research, 67, 18-25.

Irwin, H. J. (2004). An introduction to parapsychology. North Carolina: McFarland.

Jones, W. H., Russell, D. W., \& Nickel, T. W. (1977). Belief in the paranormal scale: An objective instrument to measure belief in magical phenomena and causes. Catalog of selected documents in psychology. Washington DC: American Psychological Association, 7, MS. 1577, 100 . 
BJP 180-12/5/2006-ANISH-167162

$14 \quad$ Richard Wiseman and Caroline Watt

Kirsch, I., \& Council, J. R. (1992). Situational and personality correlates of hypnotic responsiveness. In E. Fromm \& M. R. Nash (Eds.), Contemporary bypnosis research (pp. 267-291). New York: Guilford.

Korpan, C. A., Bisanz, G. L., Bisanz, J., \& Henderson, J. M. (1997). Assessing literacy in science: Evaluation of scientific news briefs. Science Education, 81, 515-532.

Lange, R. (1999). The role of fear in delusions of the paranormal. Journal of Nervous and Mental Disease, 187, 159-166.

Lange, R., \& Houran, J. (1998). Delusions of the paranormal: A haunting question of perception. Journal of Nervous and Mental Disease, 186, 637-645.

Lange, R., Irwin, H. J., \& Houran, J. (2000). Top-down purification of Tobacyk's revised paranormal belief scale. Personality and Individual Differences, 29, 131-156.

Lange, R., \& Thalbourne, M. A. (2002). Rasch scaling paranormal belief and experience: Structure and semantics of Thalbourne's Australian sheep-goat scale. Psychological Reports, 91, 1065-1073.

Lawrence, T., Edwards, C., Barraclough, N., Church, S., \& Hetherington, F. (1995). Modelling childhood causes of paranormal belief and experience: Childhood trauma and childhood fantasy. Personality and Individual Differences, 19, 209-215.

Lawrence, T. R. (1990-1991). Subjective random generations and the reversed sheep-goat effect: A failure to replicate. European Journal of Parapsychology, 8, 131-144.

Lawrence, T. R. (1995a). How many factors of paranormal belief are there? A critique of the paranormal belief scale. Journal of Parapsychology, 59, 3-25.

Lawrence, T. R. (1995b). Moving on from the paranormal belief scale: A final reply to Tobacyk. Journal of Parapsychology, 59, 131-140.

Lawrence, T. R., \& De Cicco, P. (1997). The factor structure of the paranormal belief scale: More evidence in support of the oblique five. Journal of Parapsychology, 61, 243-251.

Lawrence, T. R., Roe, C. A., \& Williams, C. (1997). Confirming the factor structure of the paranormal beliefs scale: Big orthogonal seven or oblique five? Journal of Parapsychology, 61, 13-31.

Lawrence, T. R., Roe, C. A., \& Williams, C. (1998). On obliquity and the PBS: Thoughts on Tobacyk and Thomas (1997). Journal of Parapsychology, 62, 147-151.

Lynn, S. J., \& Rhue, J. W. (1988). Fantasy proneness: Hypnosis, developmental antecedents, and psychopathology. American Psychologist, 43, 35-44.

Makasovski, T., \& Irwin, H. J. (1999). Paranormal belief, dissociative tendencies, and parental encouragement of imagination in childhood. Journal of the American Society for Psychical Research, 93, 233-247.

Marks, D. F. (1988). The psychology of paranormal beliefs. Experientia, 44, 332-337.

Matthews, R., \& Blackmore, S. J. (1995). Why are coincidences so impressive? Perceptual and Motor Skills, 80, 1121-1122.

McClenon, J. (1982). A survey of elite scientists: Their attitudes towards ESP and parapsychology. Journal of Parapsychology, 46, 127-152.

Messer, W. S., \& Griggs, R. A. (1989). Student belief and involvement in the paranormal and performance in introductory psychology. Teaching of Psychology, 16, 187-191.

Morris, R. L. (1986). What psi is not: The necessity for experiments. In H. L. Edge, R. L. Morris, J. Palmer, \& J. H. Rush (Eds.), Foundations of parapsychology: Exploring the boundaries of buman capability (pp. 70-110). London: Routledge and Kegan Paul.

Musch, J., \& Ehrenberg, K. (2002). Probability misjudgment, cognitive ability, and belief in the paranormal. British Journal of Psychology, 93, 169-177.

Newport, F., \& Strausberg, M. (2001). Americans' belief in psychic and paranormal phenomena is up over last decade. Princeton: Gallup News Service.

Otis, L. P., \& Alcock, J. E. (1982). Factors affecting extraordinary belief. Journal of Social Psychology, 118, 77-85.

Padgett, V. R., Benassi, V. A., \& Singer, B. F. (1981). Belief in ESP amoung psychologists. In K. Frazier (Ed.), Paranormal borderlands of science (pp. 66-67). Buffalo, NY: Prometheus Books. 
Palmer, J., \& Van Der Velden, I. (1983). ESP and hypnotic imagination: A group free-response study. European Journal of Parapsychology, 4, 413-434.

Pasachoff, J. M., Cohen, R. J., \& Pasachoff, N. W. (1970). Belief in the supernatural among Harvard and West African university students. Nature, 227, 971-972.

Pekala, R. J., Kumar, V. K., \& Marcano, G. (1995). Anomalous/paranormal experiences, hypnotic susceptibility, and dissociation. Journal of the American Society for Psychical Research, 89, 313-332.

Peltzer, K. (2002). Paranormal beliefs and personality among black South African students. Social Behavior and Personality, 30, 391-398.

Peltzer, K. (2003). Magical thinking and paranormal beliefs among secondary and university students in South Africa. Personality and Individual Differences, 35, 1419-1426.

Pizzagalli, D., Lehmann, D., \& Brugger, P. (2001). Lateralized direct and indirect semantic priming effects in subjects with paranormal experiences and beliefs. Psychopathology, 34, 75-80.

Pizzagalli, D., Lehmann, D., Gianotti, L., Koenig, T., Tanaka, H., Wackermann, J., \& Brugger, P. (2000). Brain electric correlates of strong belief in paranormal phenomena: Intracerebral EEG source and regional Omega complexity analyses. Psychiatry Research: Neuroimaging, 100, 139-154.

Polzella, D.J., Popp, R.J., \& Hinsman, M.C. (1975). ESP? Paper presented at a meeting of the American Psychological Association, Chicago.

Radin, D. (1997). The conscious universe: The scientific truth of psychic phenomena. New York: Harper Collins.

Roberts, M. J., \& Seager, P. B. (1999). Predicting belief in paranormal phenomena: A comparison of conditional and probabilistic reasoning. Applied Cognitive Psychology, 13, 443-450.

Roe, C. A. (1998). Belief in the paranormal and attendance at psychic readings. Journal of the American Society for Psychical Research, 90, 25-51.

Roe, C. A. (1999). Critical thinking and belief in the paranormal: A re-evaluation. British Journal of Psychology, 90, 85-98.

Rose, N., \& Blackmore, S. (2001). Are false memories psi-conducive? Journal of Parapsychology, 65, 125-144.

Royalty, J. (1995). The generalizability of critical thinking: Paranormal beliefs versus statistical reasoning. Journal of Genetic Psychology, 156, 477-488.

Saucer, P. R., Cahoon, D. D., \& Edmonds, Ed. M. (1992). The paranormal belief scale and the atheistic ideation reference scale as predictors of hypnotic suggestibility. Psychology: A Journal of Human Behavior, 29, 44-46.

Schmeidler, G. R. (1945). Separating the sheep from the goats. Journal of the American Society for Psychical Research, 39, 47-49.

Sheils, D., \& Berg, P. (1977). A research note on sociological variables related to belief in psychic phenomena. Wisconsin Sociologist, 14, 24-31.

Smith, M. D., Foster, C. L., \& Stovin, G. (1998). Intelligence and paranormal belief: Examining the role of context. Journal of Parapsychology, 62, 65-77.

Thalbourne, M. A. (1995a). Further studies of the measurement and correlates of belief in the paranormal. Journal of the American Society for Psychical Research, 89, 233-247.

Thalbourne, M. A. (1995b). Psychological characteristics of believers in the paranormal: A replicative study. Journal of the American Society for Psychical Research, 89, 153-164.

Thalbourne, M. A. (1998). Transliminality: Further correlates and a short measure. Journal of the Society for Psychical Research, 92, 402-419.

Thalbourne, M. A. (2000). Transliminality: A review. International Journal of Parapsychology, 11(2), 1-34.

Thalbourne, M. A. (2001). Measures of the sheep-goat variable, transliminality, and their correlates. Psychological Reports, 88, 339-350.

Thalbourne, M. A. (2004). A note on paranormal belief and paranormal experience: Their levels, absolute and relative. Journal of the Society for Psychical Research, 68, 115-121. 
BJP 180-12/5/2006-ANISH-167162

Thalbourne, M. A., \& Delin, P. S. (1993). A new instrument for measuring the sheep-goat variable: Its psychometric properties and factor structure. Journal of the Society for Psychical Research, 59, 172-186.

Thalbourne, M. A., \& Delin, P. S. (1994). A common thread underlying belief in the paranormal, creative personality, mystical experience and psychopathology. Journal of Parapsychology, $58,3-38$

Thalbourne, M. A., Dunbar, K. A., \& Delin, P. S. (1995). An investigation into correlates of belief in the paranormal. Journal of the American Society for Psychical Research, 89, 215-231.

Thalbourne, M. A., \& French, C. (1995). Paranormal belief, manic-depressiveness, and magical ideation: A replication. Personality and Individual Differences, 18, 291-292.

Thalbourne, M. A., \& Houtkooper, J. M. (2002). Religiosity/spirituality and belief in the paranormal: A German replication. Journal of the Society for Psychical Research, 66, 113-115.

Thalbourne, M. A., \& Nofi, O. (1997). Belief in the paranormal, superstitiousness and intellectual ability. Journal of the Society for Psychical Research, 61, 365-371.

Tobacyk, J. (1988). A Revised Paranormal Belief Scale. Unpublished manuscript, Louisiana Tech University, Rushton, LA.

Tobacyk, J. (1995a). What is the correct dimensionality of paranormal beliefs? A reply to Lawrence's critique of the paranormal belief scale. Journal of Parapsychology, 59, 27-46.

Tobacyk, J. (1995b). Final thoughts on issues in the measurement of paranormal beliefs. Journal of Parapsychology, 59, 141-145.

Tobacyk, J., \& Milford, G. (1983). Belief in paranormal phenomena: Assessment instrument development and implications for personality functioning. Journal of Personality and Social Psychology, 44, 1029-1037.

Tobacyk, J., Miller, M. J., \& Jones, G. (1984). Paranormal beliefs of high school students. Psychological Reports, 55, 255-261.

Tobacyk, J., \& Thomas, A. (1997). How the Big Orthogonal Seven is really the Oblique Seven. Journal of Parapsychology, 61, 337-342.

Wagner, M. W., \& Monnet, M. (1979). Attitudes of college professors toward extrasensory perception. Zetetic Scholar, 5, 7-17.

Wagner, M. W., \& Ratzeburg, F. H. (1987). Hypnotic suggestibility and psi belief. Psychological Reports, 60, 1069-1070.

Wierzbicki, M. (1985). Reasoning errors and belief in the paranormal. Journal of Social Psychology, 125, 489-494.

Williams, L. M., \& Irwin, H. J. (1991). A study of paranormal belief, magical ideation as an index of schizotypy and cognitive style. Personality and Individual Differences, 12, 1339-1348.

Wiseman, R., Greening, E., \& Smith, M. (2003). Belief in the paranormal and suggestion in the seance room. British Journal of Psychology, 94, 285-297.

Wiseman, R., \& Morris, R. L. (1995). Recalling pseudo-psychic demonstrations. British Journal of Psychology, 86, 113-125.

Wiseman, R., \& Smith, M. D. (2002). Assessing the role of cognitive and motivational biases in belief in the paranormal. Journal of the Society for Psychical Research, 66, 157-166.

Wiseman, R., \& Watt, C. (2002). Experimenter differences in cognitive correlates of paranormal belief and in psi. Journal of Parapsychology, 66, 371-385.

Zusne, L., \& Jones, W. H. (1982). Anomalistic psychology: A study of extraordinary phenomena of behavior and experience. Hillsdale, NJ: Erlbaum.

Received I8 February 2005; revised version received 30 August 2005 


\section{Author Queries}

JOB NUMBER: 180

JOURNAL: BJP

Q1 In the reference Irwin, Thalbourne, 2001, it is unclear, please check that this reference has been included in the list.

Q2 kindly provide full form of SAT.

Q3 References: Salter \& Routledge, 1971; Irwin, 1991 were found in text, but not in list, kindly check.

Q4 In the reference, Brugger et al., 1993a, the year has been changed to 1993b in order to match the list, kindly check.

Q5 In the reference, Brugger, Gamma, Müri, Schäfer, and Taylor (1993b), the year has been changed to $1993 \mathrm{a}$, in order to match the list, kindly check.

Q6 Reference, Irwin, 1991a is found in list, but not in text, kindly check. 